\title{
Fibronectin is distinctly downregulated in murine mammary adenocarcinoma cells with high metastatic potential
}

\author{
ALEJANDRO J. URTREGER ${ }^{1 *}$, SANTIAGO E. WERBAJH ${ }^{2 *}$, FRANK VERRECCHIA $^{3}$, ALAIN MAUVIEL $^{3}$, \\ LYDIA I. PURICELLI ${ }^{1}$, ALBERTO R. KORNBLIHTT ${ }^{2}$ and ELISA D. BAL DE KIER JOFFÉ ${ }^{1}$ \\ ${ }^{1}$ Área Investigación, Instituto de Oncología ‘Ángel H. Roffo’, Universidad de Buenos Aires; ${ }^{2}$ Laboratorio de Fisiología \\ y Biología Molecular, Departamento de Fisiología, Biología Molecular y Celular, IFIByNE-CONICET, Facultad de \\ Ciencias Exactas y Naturales, Universidad de Buenos Aires, Ciudad Universitaria, Buenos Aires, \\ Argentina; ${ }^{3}$ INSERM U697, Institut de Recherche Sur La Peau, Université Paris VII, \\ Pavillon Equerre-Bazin, Hôpital Saint Louis, 75010 Paris, France
}

Received August 3, 2006; Accepted September 11, 2006

\begin{abstract}
In the present work we used a murine mammary cancer model of two related adenocarcinomas with different lung metastasizing abilities, to compare their global gene expression profiles. Clontech Atlas mouse cDNA microarrays of primary cultured tumor cells were employed to identify genes that are modulated in the more metastatic variant MM3 relative to its parental tumor M3. A total of 88 from 1,176 genes were differentially expressed in MM3 primary cultures, most of them $(n=86)$ were upregulated. Genes were grouped according to their functions as associated with signal transduction and transcription regulation (e.g. Stat 1 and Zfp 92), with cell adhesion and motility (cadherin 1, fibronectin), with invasion and angiogenesis (uPA, $72 \mathrm{kDa}$ MMP2), with the regulation of cell proliferation and cell death (cyclins G and A2, TNF), and also included growth factors and receptors, oncogenes and tumor suppressors genes (p107, TGFß2, TBR-I, PDGFR). Only 2 genes, TTF1 and fibronectin $(\mathrm{FN})$, showed a significant downregulation. Notably FN expression, loss of which has been associated with a malignant phenotype, was reduced about 19-fold in the more metastatic MM3 cells. Previously known differences in expression patterns associated with the metastatic capacity of MM3 and M3 adenocarcinomas, including downregulation of FN or upregulated expression of TGFß and proteases, were confirmed by the array data. The fact that FN was one
\end{abstract}

Correspondence to: Dr Elisa D. Bal de Kier Joffé, Área Investigación, Instituto de Oncología 'Ángel H. Roffo', Av. San Martín 5481, (C1417DTB) Buenos Aires, Argentina

E-mail: elisabal@fmed.uba.ar

${ }^{*}$ Contributed equally

Key words: fibronectin, cDNA arrays, metastasizing ability, murine mammary adenocarcinoma of the only two genes significantly down-regulated out of the 1,176 genes analyzed stresses the hypothesis that FN may behave as an important metastasis suppressor gene in mammary cancer.

\section{Introduction}

The major pathological effect of cancer is caused by the invasion of malignant cells to surrounding tissues and the subsequent metastasis to vital organs. The metastatic process involves the detachment and infiltration of the cells from the original primary tumor, intravascular invasion, transportation in the blood, arrest in the microvasculature, extravasation, and finally, proliferation at the target organ $(1,2)$. This process involves the participation of numerous molecules with specific activities, such as growth factors and their specific receptors, cell adhesion molecules, cytoskeleton proteins, extracellular matrix components (ECM) as fibronectin $(\mathrm{FN})$, and proteolytic enzymes such as plasminogen activators (uPA) and metalloproteinases (MMP) (3). Moreover, the molecular requirements for some of these steps may be tissue specific. In fact, the proclivity that some tumors have for specific organs, such as breast carcinomas for bone and lung, was described more than a century ago and is still a matter of analysis (4-6).

It is accepted that tumors are heterogeneous for many properties and contain subpopulations of more or less aggressive cells that differ in many of their biochemical and biological characteristics, such as growth rate, karyotype, expression of hormone receptors, and their invasive and metastatic capability (7). Taking advantage of this characteristic, many experimental models, useful to study critical determinants of tumor progression, have been developed $(4,8)$. A mammary cancer model syngeneic in BALB/c of two related adenocarcinomas with different lung metastasizing abilities, was established by an in vivo procedure more than 20 years ago in our institute (9). MM3 adenocarcinoma variant was selected after 10 successive re-transplantations of M3 lung metastases into the flank of syngeneic mice, procedure that led to an enrichment of its lung metastatic potential. These tumors, together with their derived continuous cell lines (10), have 
been extensively used to analyze critical molecular determinants of breast tumor growth and dissemination (10-15).

Although there is extensive knowledge of the changes that endow tumor cells with their metastatic functions, this is a subject of debate. Further insight into the complexity of the metastatic process can be approached employing the new technologies available to analyze the expression of hundreds of genes simultaneously. In the present work we compared the global gene expression profiles obtained by cDNA microarrays of M3 and MM3 primary cultures in order to identify those genes that are modulated in the more metastatic variant MM3 relative to its parental tumor M3. A total of 86 significantly upregulated genes ( $>2.7$-fold) were identified in MM3 primary cultures, while the expression of only two genes was significantly downregulated $(<0.33$-fold). The expression level of FN, a plasma and extracellular matrix glycoprotein which loss has been associated with the acquisition of a malignant phenotype (16), was reduced about 19-fold $(<0.05$ fold) in the more metastatic MM3 cells, confirming our previous findings employing other methodologies $(9-12,17)$. The fact that FN was one of the only two significantly downregulated genes among the 1,176 genes analyzed stresses the hypothesis that FN may behave as a metastasis suppressor gene in mammary cancer.

\section{Materials and methods}

Reagents and antibodies. Medium for cell culture (MEM, Cat. no. 41500) was from Gibco Life Technologies (Rockville, MD). Fetal calf serum (FCS) was from GENSA (Buenos Aires, Argentina). Triton X-100 was obtained from Dr J.T. Baker (Phillipsburg, NJ). All other reagents for polyacrylamide gel electrophoresis and zymography were obtained from Bio-Rad (Richmond, CA). Trypsin, pronase, DNase and anti-human fibronectin antibodies were obtained from Sigma Co. (St. Louis, MO). Anti-PDGFR2- $\alpha$, anti-CD31, anti-retinoblastoma and anti- $\beta$-actin antibodies were purchased from Santa Cruz Biotechnology (Santa Cruz, CA). Anti-E-cadherin and antiStat1 antibodies were from Transduction Laboratories (San Diego, CA). Horseradish peroxidase conjugated anti-rabbit and anti-mouse antibodies, Hybond-P membranes and chemiluminescence reagents (ECL) were from Amersham (Aylesbury, UK).

Tumors. An in vivo selected model of two related transplantable mammary adenocarcinomas with different lung metastatic potential was used in this study (9). Briefly, M3 tumor presents a latency of 6-8 days and has a $40 \%$ incidence of lung metastases. MM3 variant was previously obtained in our laboratory following successive subcutaneous (s.c.) trochar implants of M3 lung metastases into the flank of syngenic mice. Once MM3 achieved a stable growth and metastatic behavior, it was further maintained by grafts of s.c. tumor fragments. This variant presents a longer latency (12-14 days) and a $95 \%$ incidence of lung metastases (13). Both tumors were maintained by s.c. trocar implants into female BALB/c mice. Animals were maintained under the guidelines of the National Institutes of Health and approved protocols of institutional Animal Care and Use Committee of the Institute of Oncology ‘Ángel H. Roffo'.
Primary culture. To reduce the risk of contaminating tumor parenchymal cells with stromal and/or other host cells, primary cultures of M3 and MM3 tumors were prepared, as previously described (13). Briefly, cell suspensions were obtained by enzymatic digestion of tumor fragments with $0.01 \%$ Pronase and $0.0035 \%$ DNase in MEM medium. Viable cells were counted employing trypan-blue exclusion test. Cells were cultured at $37^{\circ} \mathrm{C}$ in plastic flasks in a humidified $5 \% \mathrm{CO}_{2}$ air atmosphere, in MEM supplemented with 10\% FCS, 2 mM L-glutamine and $80 \mu \mathrm{g} / \mathrm{ml}$ gentamycin. M3 and MM3 cell monolayers were mostly composed of epithelioid polyhedric cells with less than $2 \%$ contaminating macrophages and fibroblast-like cells (13).

In vivo metastasis assay. To assay their spontaneous metastatic ability, M3 and MM3 cells, harvested from subconfluent primary cultures during the exponential growth phase by treatment with Trypsin-EDTA, were washed thoroughly with MEM and resuspended in the same medium. Non-anesthetized $\mathrm{BALB} / \mathrm{c}$ female mice were inoculated s.c. into the left flank with $2 \times 10^{5}$ viable cells of each tumor type, in a volume of $200 \mu 1$ of serum-free MEM. Six weeks after inoculation animals were sacrificed and lungs were fixed in Bouin's solution. The number and size of surface lung nodules was determined under a dissecting microscope. Two independent experiments were performed.

\section{RNA extraction}

Differential hybridization of Atlas ${ }^{\mathrm{TM}}$ mouse cDNA expression arrays. Total RNA from M3 and MM3 cell monolayers was obtained using an RNeasy kit (Qiagen, Valencia, CA) and treated with DNase I to avoid genomic DNA contamination of reverse transcription reactions. Radioactive cDNA synthesis was carried out as described in the Atlas cDNA expression arrays user manual (Clontech, San Diego, CA). Equal amounts of ${ }^{33} \mathrm{P}$-radiolabeled cDNAs $\left(10^{7} \mathrm{cpm}\right)$ from M3 and MM3 RNA samples were hybridized in parallel to Atlas 1.2 mouse cDNA expression arrays (Clontech) for $18 \mathrm{~h}$ at $68^{\circ} \mathrm{C}$. Then filters were washed four times in 2X SSC and 1\% SDS for $30 \mathrm{~min}$ at $68^{\circ} \mathrm{C}$ and twice in $0.1 \mathrm{X} \mathrm{SSC}$ and $0.5 \% \mathrm{SDS}$ at $68^{\circ} \mathrm{C}$, according to the manufacturer's recommendation. Membranes were then exposed to Eastman Kodak Co. phospho-screens for 6 days. Hybridization signals were quantified with a Storm 840 phosphorimager using ImageQuant software (Amersham) and normalized against the mRNA levels of two house-keeping genes in the same samples: $B$-actin and type-2A and protein phosphatase (PPA2). Significant modulation of gene expression was arbitrarily set to a ratio threshold of 2.7. Three independent experiments were performed.

Western blot analysis. Cell lysates were prepared by incubating the primary cultures in lysis buffer (50 mM HEPES, pH 7.5, $150 \mathrm{mM} \mathrm{NaCl}, 1 \mathrm{mM}$ EDTA, $2.5 \mathrm{mM}$ EGTA, 1\% Tween-20, $10 \mathrm{mM}$ ß-glycerophosphate, $0.1 \mathrm{mM}$ orthovanadate, $10 \mathrm{mg} / \mathrm{ml}$ leupeptin, $10 \mathrm{mg} / \mathrm{ml}$ aprotinin, $1 \mathrm{mM}$ DTT, and $0.1 \mathrm{mM} \mathrm{PMSF}$ ) on ice for $40 \mathrm{~min}$. The lysates were cleared by centrifugation $\left(12,000 \mathrm{rpm}, 15 \mathrm{~min}\right.$ at $\left.4^{\circ} \mathrm{C}\right)$. Total protein concentrations were determined using the Bradford Reagent (Bio-Rad). Cell extracts (60 $\mu \mathrm{g}$ protein) were separated on 7.5 or $10 \%$ SDSpolyacrylamide gel, and separated proteins were transferred 


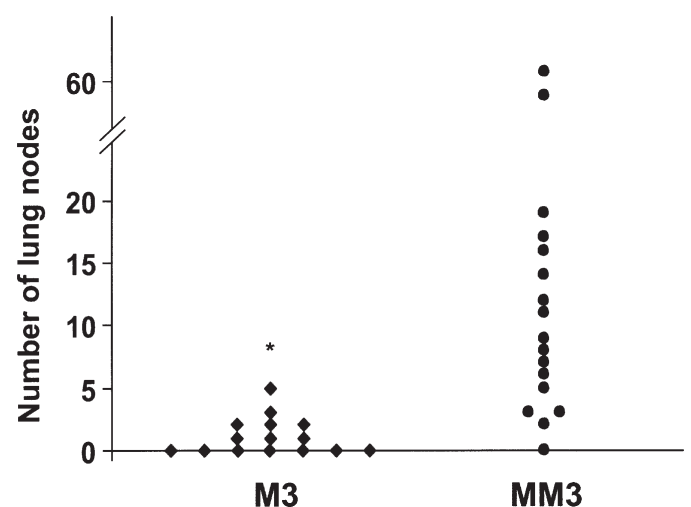

Figure 1. Spontaneous lung metastasizing ability of primary cultures derived from M3 and MM3 murine mammary adenocarcinomas. Cells were injected s.c. and 6 weeks after inoculation animals were sacrificed and the number of lung foci was recorded. The figure shows the results of at least 2 independent experiments. ${ }^{*}$ p $<0.01$ vs. MM3 cells. Kruskal-Wallis test.

onto Hybond-P membranes using semidry blotting (Bio-Rad). The membranes were blocked for $1 \mathrm{~h}$ with $5 \%$ skim-milk in TBST buffer (20 mM Tris- $\mathrm{HCl}, \mathrm{pH} 7.6 / 137 \mathrm{mM} \mathrm{NaCl} / 0.5 \%$ Tween-20), and incubated with the first antibodies overnight at $4^{\circ} \mathrm{C}$. Blots were washed three times with TBST buffer, then incubated for $1 \mathrm{~h}$ with a secondary antibody coupled to horseradish peroxidase. Detection was performed by chemiluminescence. Bands were quantified by scanning on a digital GS-700 densitometer and the resulting data processed with Molecular Analyst software (Bio-Rad). Membranes blotted with anti- $\beta$-actin antibodies were used as loading and transfer control.

\section{Results}

In vivo metastatic behavior of M3 and MM3 primary cultures. Before initiating the cDNA microarray experiments, the spontaneous metastatic capacity of M3 and MM3 primary cultures was studied, in order to confirm that cultured cells did not lose the differences in their metastasizing ability shown by the non-cultured tumor variants (9).

MM3 primary cultured cells inoculated s.c. into syngeneic mice were significantly more metastatic than M3 ones. As shown in Fig. 1, 16/17 (95\%) animals inoculated with MM3 cells developed spontaneous lung metastasis with a median number of 11 (range 0-62), while only 8/15 (53\%) mice inoculated with M3 cells developed 1 (0-6) foci per mouse.

cDNA microarray analysis. The broad coverage Clontech Atlas 1.2 mouse cDNA arrays were used to profile the differential expression of genes involved in many crucial cellular pathways and functions associated with metastatic dissemination, employing our murine mammary cancer model of MM3 adenocarcinoma, highly metastatic to lung and its parental low metastatic mammary tumor M3.

It is important to note that cDNA was prepared with RNA extracted from primary cultures established from a pool of three s.c. tumors for each variant, in order to avoid sample contamination with RNA from stromal or migrating host cells.

Although there was certain variability in the magnitude of differential expression between experiments, only uni-

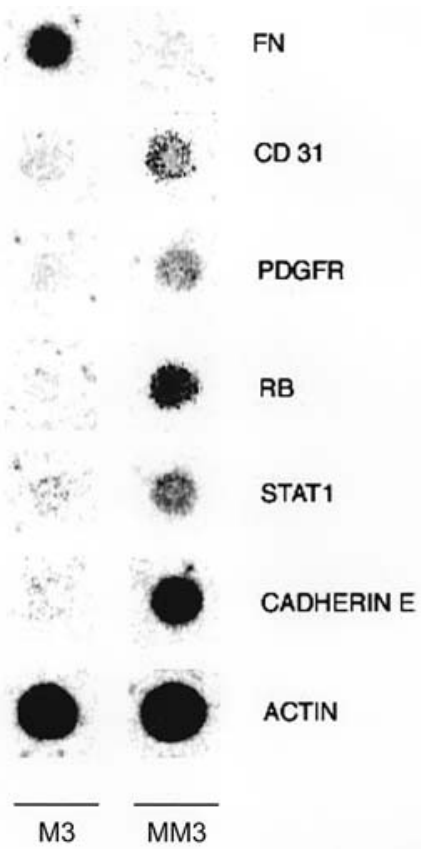

Figure 2. Representative spots of upregulated and downregulated genes in cDNA microarrays for M3 and MM3 cells. Total RNA from M3 and MM3 cell monolayers were obtained and ${ }^{33} \mathrm{P}$-radiolabeled cDNAs were prepared and hybridized in an Atlas 1.2 mouse cDNA expression arrays.

directional consistent changes were taken into account for further analysis. Of the 1,176 genes analyzed, a set of 88 genes showed differential expression in a significant and consistent way in MM3 cells compared to M3 ones. Interestingly, most of them were upregulated. A list of these genes, grouped into several functional categories and ranked according to their ratio value, is presented in Table I. According to these results, the high metastatic phenotype of MM3 cells could involve the augmented expression of genes associated with the regulation of signal transduction and transcription (e.g. STAT1, Zfp 92, Zfp 36, interferon regulatory factors 1, 2, 7, and E2F transcription factor 5), with cell adhesion and motility (cadherin 1, $\alpha 2$ integrin, gap junction membrane channel proteins $\alpha 1$ and 3, kinesin family member 3A, thrombospondin, syndecans 1 and 3, keratin complex 1), with invasion and angiogenesis (uPA, $72 \mathrm{kDa}$ MMP2, cathepsin W, granzyme C), with the regulation of cell proliferation and cell death [cyclins $G$ and A2, CDKN1A, cyclin dependent kinase protein 1A (p21), $\mathrm{TNF}$, and also including several growth factors and receptors, oncogenes and tumor suppressors (lung carcinoma myc related 1, p107 retinoblastoma like 1, proto-oncogene c-rel, C-CSF, TGFß2, TGFß receptor 1, PDGF receptor B). A large proportion of the upregulated genes in the highly metastatic MM3 cells are believed to be involved in signal transduction and gene expression regulation. Only two genes FN and TTF1 were significantly downregulated in MM3 cells with expression below the chosen cut-off threshold of 0.33 .

Validation of differential expression. To confirm the differential expression results, a subset of six genes, five of them upregulated and $\mathrm{FN}$ as the main downregulated gene, were selected (Fig. 2) and their expression at protein level by Western blotting was analyzed in M3 and MM3 primary 
Table I. List of upregulated (A) and downregulated (B) genes by microarray analysis (MM3/M3 primary cultures).

(A) Signal transduction and gene expression regulators

1. X57621 Nuclease sensitive element binding protein 128.8

2. S81932 Distal-less homeobox 3

24.89

3. U41626

Split hand/foot deleted gene 1

23.83

4. U47104

Zinc finger protein 92

5. Y07836

Basic helix-loop-helix domain

containing class B2

6. M58566 Zinc finger protein 36. C3H type-like 1

7. U58533

Est2 repressor factor

8. L36435

v-maf musculoaponeurotic fibrosarcoma

oncogene family, protein B (avian)

9. U69270 LIM domain binding

10. U53925 Host cell factor C1

11. U06924 Signal transducer and activator of

transcription 1 (STAT1)

12. M31042 Immediate early response 2

13. M21065 Interferon regulatory factor 1

14. X80339 Sine oculis-related homeobox 1 homolog

(Drosophila)

15. U36340 Kruppel-like factor 3 (basic)

16. X61754 Heat shock factor 2

17. U19119 Interferon inducible protein 1

18. J03168 Interferon regulatory factor 2

19. M20157 Early growth response 1

20. L13204 Forkhead box J1

21. U66918 Short stature homeobox 2

22. X86925 E2F transcription factor 5

23. D26046 AT motif binding factor 1

24. X63507 Homeo box C10

25. U73037 Interferon regulatory factor 7

26. L35949 Forkhead box F1a

27. AF013282 T-box 14

28. X61753 Heat shock factor 1

29. U09419 Nuclear receptor subfamily 1 group H member 2

30. U52951 Enhancer of zeste homolog 2 (Drosophila)

31. $\$ 74227$

32. U89876

33. D13801

TEA domain family member 1

22.71

20.74

18.29

15.33

12.91

9.49

7.43

6.91

6.88

6.79

6.42

6.32

6.06

5.94

5.80

5.66

5.13

5.04

4.96

4.69

4.64

4.46

4.18

4.15

3.94

3.80

3.74

3.57

RNA and export factor binding protein $1 \quad 3.43$

POU domain, class 6 , transcription factor $1 \quad 3.26$

Transducin-like enhancer of split 3, $\quad 3.26$

Homolog of Drosophila $\mathrm{E}(\mathrm{spl})$

35. U41671 Zinc finger proliferation 1

36. U47008 Ngfi-A binding protein 1

3.13

2.83

(A) Growth factors, cytokines, oncogenes and tumor suppressors

1. L34169 Thrombopoietin 48.91

2. U27177 Retinoblastoma-like 1 (p107)

48.91

3. $\mathrm{X} 15842$

Reticuloendotheliosis oncogene

22.99

4. $\mathrm{X} 81580$

Insulin-like growth factor binding protein $2 \quad 15.97$

5. M64292

Growth factor - B-cell translocation gene 2

15.97

anti-proliferative

6. X56135 Prothymosin $\alpha$
Table I. Continued.

(A) Growth factors, cytokines, oncogenes and tumor suppressors

7. M86671 Interleukin 12b 8.03

8. X04367 Platelet derived growth factor receptor, 6.94 ß polypeptide

9. X57413 Transforming growth factor $\beta 2$ precursor 5.95 (TGF-beta 2; TGFB2)

10. Z11886 Notch gene homolog 1 (Drosophila) 5.30

11. X82327 Myeloblastosis oncogene-like 1 4.39

12. U66202 Fibroblast growth factor $13 \quad 4.18$

13. X05010 Colony stimulating factor 1 (macrophage) 4.17

14. U37522 Tumor necrosis factor (ligand) 3.86 superfamily member 10

15. X13945 Lung carcinoma myc related oncogene $1 \quad 3.84$

16. AF039661 TGFß receptor type III (betaglycan) 3.77

17. X70514 Nodal 3.69

18. U21011 mutS homolog 2 (E. coli) 3.23

19. D25540 Transforming growth factor $\beta$ receptor $1 \quad 3.10$ (TGFß receptor 1 ; TGFR1)

20. X77113 Growth differentiation factor 9

(A) Adhesion, motility and cytoskeleton proteins

1. D12645 Kinesin family member 3A 18.06

2. X06115 Cadherin $1 \quad 14.75$

3. S69407 Endoglin 11.99

4. X12875 L1 cell adhesion molecule $\quad 8.25$

5. M28698 Keratin complex 1, acidic, gene $19 \quad 7.34$

6. M87276 Thrombospondin $1 \quad 7.04$

7. M63801 Gap junction membrane channel protein $\alpha 1 \quad 6.60$

8. L06039 Platelet/endothelial cell adhesion molecule 4.63 (PECAM1). CD31 antigen

9. U44955 Gap junction membrane channel protein $\alpha 3 \quad 4.65$

10. M34510 CD14 antigen 4.61

11. D14340 Tight junction protein $1 \quad 3.98$

12. Z22532 Syndecan $1 \quad 3.74$

13. U52826 Syndecan $3 \quad 3.03$

14. X75427 Integrin $\alpha 2 \quad 2.87$

(A) Cell proliferation and cell death regulators

1. AA289122 CDC28 protein kinase regulatory sub $2 \quad 27.78$

2. U09507 Cyclin-dependent kinase inhibitor 1A (P21) 8.41

3. Z37110 Cyclin G1 7.49

4. M22115 Homeo box A1 6.46

5. Z26580 Cyclin A2 4.55

6. L08235 Clusterin 3.90

(A) Invasion and angiogenesis

$\begin{array}{lll}\text { 1. AF014941 } & \text { Cathepsin W } & 7.49 \\ \text { 2. X12822 } & \text { Granzyme C } & 5.63 \\ \text { 3. M84324 } & \text { 72-kDa type IV collagenase type; } & 4.23 \\ & \text { 72-kDa gelatinase; gelatinase A; } & \\ & \text { matrix metalloproteinase 2 } & \\ \text { 4. M75716 } & \alpha 1 \text { protease inhibitor 2 } & 2.75 \\ \text { 5. X02389 } & \text { Urokinase type plasminogen activator } & 2.71\end{array}$


Table I. Continued.

\section{(A) Other}

$\begin{array}{llll}\text { 1. J03752 } & \text { Microsomal glutathione S-transferase 1 } & 6.89 \\ \text { 2. AB001607 } & \text { Prostaglandin I2 (prostacyclin) synthase } & 5.33 \\ \text { 3. U34920 } & \begin{array}{l}\text { ATP-binding cassette, sub-family G } \\ \text { (WHITE), member 1 }\end{array} & 4.83 \\ \text { 4. M14757 } & \begin{array}{l}\text { ATP-binding cassette, sub-family B } \\ \text { (MDR/TAP), member 1B }\end{array} & 4.31 \\ \text { 5. U20372 } & \text { Calcium channel, voltage-dependent, B3 sub } & 3.77\end{array}$

(B) Adhesion, motility and cytoskeleton proteins

$$
\text { 1. X82402 Fibronectin } 1
$$

(B) Growth factors, cytokines, oncogenes and tumor suppressors

$\begin{array}{lll}\text { 1. X83974 } & \begin{array}{l}\text { RNA polymerase I transcription } \\ \text { termination factor 1 (TTF1) }\end{array} & 5.65\end{array}$

Data are the average (mean) of two independent experiments between primary cultures of the highly metastatic MM3 mammary adenocarcinoma compared to the parental low metastatic M3 cells (MM3/ M3). Values were corrected with the expression of two house-keeping genes (PPA2 and ACTIN) already included in the arrays. Only ratios $>2.7$ - or $<0.33$-fold were considered significant.

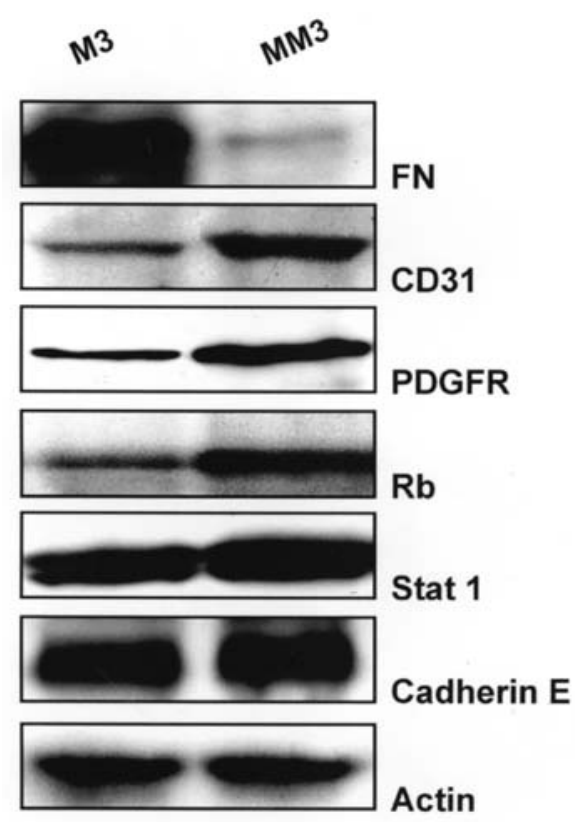

Figure 3. Validation of cDNA microarray results by Western blot analysis. The expression of 5 upregulated genes and the downregulated FN gene were selected to confirm Atlas 1.2 mouse cDNA expression array results. Actin expression was used as protein loading control.

culture lysates. As shown in Fig. 3 a very good correlation between both methodologies was observed, thus validating the cDNA microarray results.

\section{Discussion}

Tumor metastasis is a complex and dynamic process that is expected to involve alterations in many genes and transcriptional programs. However, it is unknown how and when metastasis genes are activated along the process of tumorigenesis and whether specific metastasis genes might have a function in primary tumor growth (4). The cDNA microarray methodology provides an interesting approach to gain insight into the molecular events that underlie metastasis dissemination of mammary cancer cells, as it allows analyzing as a conjunct a set of differentially expressed genes between primary tumors with distinct metastatic ability.

To avoid undesired contamination with non-parenchymatous cells, the cDNA microarray procedure was carried out in primary cultures of M3 and MM3 adenocarcinomas of almost only tumor epithelial cells (13). Before performing the molecular analysis we confirmed that primary cultures maintained the same spontaneous metastatic ability to the lungs as shown by the uncultured cells (9).

We identified a set of 88 genes, out of the 1,176 genes analyzed, that were differentially expressed in a significant and consistent way in the more metastatic MM3 mammary adenocarcinoma cells compared to the parental less metastatic M3 ones. These genes encode extracellular products including growth and survival factors and their receptors (TGFß2, FGF, PDGFR-B), chemokines (interleukin 12b), extracellular matrix components (FN) and proteases (uPA, MMP-2). They also include intracellular enzymes (prostaglandin 12 synthase) as well as transcriptional and signaling regulators (STAT1, E2F5, Zn finger proteins 92 and 36).

Some of these genes are known to be associated with proliferation, malignant transformation and metastasis in breast and other tissues, whereas, almost no studies have been reported, for addressing related functions for Zfp 92, Zfp 3611, Bhlhb2, Hcf1 and Ldb1 genes. For validation purposes we have chosen five genes upregulated in MM3 cells which potential relationship with tumor progression and the metastatic phenotype will be detailed below.

Relating to our observation that PDGFR-B gene expression was upregulated in MM3 cells, other authors have reported that the overexpression and/or activation of both PDGF receptors $A$ and $B$ are associated with migration and dissemination of malignant cells of different tissue origin $(18,19)$.

STAT1 is a member of the family of signal transducers and activators of transcription that plays central roles in the responses of cells to cytokines and cell cycle regulation. Specifically STAT1 and STAT2 are intimately involved in the response of cells to interferons (20). Contradictory findings regarding its expression and/or activation status in tumors have been reported, and furthermore, whether STAT1 affects tumor growth and metastasis is still unclear $(21,22)$. We found that STAT1 is about 6-fold upregulated in the more metastatic MM3 adenocarcinoma. This difference may be associated with the fact that several cycle regulators, such as cyclins $\mathrm{G}$ and $\mathrm{A}$ and CDKN1A (encoding p21), as well as a group of gene expression regulators involved in the response to interferon, namely interferon regulatory factors 1,2 and 7 
and interferon inducible protein 1, were also strongly upregulated. Although retinoblastoma protein expression (Rb105) has been inversely correlated with proliferation rate and metastatic potential in breast adenocarcinomas, this correlation has not always been observed either for the Rb105 or for the related proteins p107 and p130 in different tumors $(23,24)$. In the present study we found a very strong upregulation of the retinoblastoma-like 1 (p107) gene in the more metastatic MM3 tumor, a finding that deserves further investigation.

The E-cadherin/ß-catenin cell adhesion system is often downregulated in epithelial tumors. This is thought to play an important role in cancer invasion and metastasis (25). Surprisingly, the cDNA microarray analysis revealed the E-cadherin expression was upregulated about 15 -fold in the metastastic MM3 adenocarcinoma. Related to our finding, other authors have found a correlation between aberrant expression of E-cadherin or B-catenin with lymph node metastasis, survival rate and survival length in breast cancer (26). To further support the notion that in some cases an aberrantly enhanced expression of this cell adhesion molecule may occur in cancer, Cavallaro and Christofori (27) have reported that metastatic prostate cancer shows strong Ecadherin expression while a transient downregulation of this molecule may occur in localized prostate cancer.

The platelet/endothelial cell adhesion molecule (CD31/ PECAM1), expressed at the plasma membrane of platelets and endothelial cells, has been widely used as a marker of tumor angiogenesis and poor prognosis in cancer (28). Curiously, CD31 has also been detected in human, mouse and rat solid tumor lines (29). We found that MM3 cells overexpressed this endothelial cell marker about 5-fold relative to M3 parental tumor cells. In agreement with our finding, Righi et al (30) have recently reported that a subset of breast ductal in situ carcinomas express CD31, and demonstrated that CD31 overexpression reverted the undifferentiated morphology and aggressive behavior of MDA-MB-231 cells, indicating its active role in the morphogenesis of breast ductal in situ carcinomas. We still do not know the significance of CD31 expression in our murine mammary cancer model.

Previously known differences in expression patterns between the parental M3 and its highly metastatic variant MM3 were confirmed by the array data. We had previously found, in coincidence with the present results, that MM3 tumor secretes about 3- to 4-fold more uPA than M3 (14). Furthermore, the critical role of uPA in the invasive phenotype of this mammary tumor model was also demonstrated in vivo (31). The present analysis revealed that several members of the TGFßs/TßRs system [TGFß2, TGFß receptor 1 (TßR-1), TGFß receptor type III] were coordinately upregulated in MM3 adenocarcinoma. These results are validated by our previous studies reporting that MM3 showed a higher expression at protein level of the different isoforms of TGFß and its specific receptors, as compared with the parental M3 tumor, suggesting that the TGFß effects on cell proliferation and invasive capability would be favoring tumor progression (15).

While most of the differentially expressed genes were upregulated, only two genes showed a significant downregulation in the highly metastatic adenocarcinoma MM3. The expression of TTF-1, an RNA polymerase I transcription terminator factor, was reduced about 6-fold, and this fact could be impairing transcriptional regulation of ribosomal RNAs. Little is known about TTF-1 expression in cancer. Monitto et al (32) have found, in a murine adenocarcinoma model, that TTF-1 gene expression is decreased in a cell line that induces cachexia in NMRI nude mice, as compared with histologically similar cells that do not induce this paraneoplasic syndrome.

On the contrary, downregulation of FN is a well-known phenomenon associated with cancer $(16,33)$. Our cDNA microarray analysis is distinctly and considerably (about 19fold) downregulated in MM3 cells among 1,176 genes. Fibronectin is a plasma and extra-cellular matrix glycoprotein that plays key roles in the adhesive and migratory behavior of cells, being involved in processes such as embryonic development, hemostasis and wound healing as well as oncogenic transformation and metastasis $(34,35)$. It has been demonstrated that some neoplastic cells synthesize FN at a lower rate than normal ones, or do not synthesize it at all, and are unable to deploy FN for an efficient adhesion or cannot retain FN on their surfaces $(16,33)$. Conversely, reappearance of FN expression elicited by stable FN cDNA transfection or signaling activation has been shown to revert tumorigenic phenotypes $(11,36)$. Furthermore, there is strong evidence indicating that the metastatic potential is inversely correlated with FN expression $(37,38)$.

In previous work we found that the highly metastatic MM3 tumor variant did not express FN either at mRNA or at protein levels while the poorly metastatic parental tumor M3 expressed and deployed a FN network in the extracellular matrix. These results were confirmed by our present study, employing the cDNA microarray analysis and immunoblotting and immunocytochemistry validation. The relationship between FN loss and metastasis was further supported by our finding (17) that a continuous cell line derived from MM3 primary cultures (termed LMM3) (10), permanently transfected with constructs expressing full length FN cDNA under the control of a viral promoter, exhibited reduced spontaneous and experimental metastatic capacity, without modulation of the primary tumor growth. This less aggressive behavior was accompanied with an in vitro reduced migratory ability (17) and the deregulation of the UPA/uPAR system (39). In other work we have explored the molecular bases of the downregulation of FN expression in the highly metastatic MM3 cells. Using the very sensitive RT-PCR procedure we estimated that the levels of FN mRNA were about 40-fold lower in MM3 that in M3 cells and we attributed this difference to a reduced transcriptional activity involving the 220-bp proximal promoter region (11). The FN proximal promoter presents several SP1 sites (40). This could be related to the fact that the zinc finger protein 92 (Zfp 92), a transcription factor related to the SP1 family, was upregulated about 20-fold in MM3 cells compared to M3 ones (Table I). Since Zfp 92 may behave as a transcriptional repressor, its overexpression could cause the downregulation of the FN gene.

Contrary to our observations (37) it has been found that FN gene expression, as analyzed by cDNA microarrays, is downregulated in MDA-MB-435 human mammary carcinoma cell line stably transfected with the known metastasis suppressor gene NM23. In another epithelial tumor type, the 
papillary thyroid carcinoma, $\mathrm{FN}$ is markedly upregulated in comparison with normal thyroid tissue (41). On the other hand, and in agreement with us, Mackay et al (42) have also reported a significant downregulation of $\mathrm{FN}$ associated with ERBB2 overexpression, an established adverse prognostic factor in breast cancer, though in their model FN was one out of 25 significantly downregulated genes. Similar results were obtained analyzing the differential gene and protein expression in metastatic lymph nodes of primary breast cancers (43). Our present results, showing that the reduction of FN expression in the highly metastatic mammary tumor MM3 cells is a very rare event in an environment of upregulated genes, places FN downregulation in a new context, and may help to better understand its role in tumor progression, supporting the hypothesis of $\mathrm{FN}$ as a main metastasis suppressor gene in mammary cancer.

\section{Acknowledgements}

This work was supported by the following grants: FONCyT (PICT 14088, Préstamo BID 1728-OC-AR) and UBACyT (M068) awarded to E.B.K.; CONICET (Res \#1105/04) awarded to A.J.U. and FONCyT (PICT 13262, Préstamo BID 1201-OC-AR) and Fundación Antorchas awarded to A.R.K. A.R.K. is an International Research Scholar of the Howard Hughes Medical Institute.

\section{References}

1. Condeelis J, Singer RH and Segall JE: The great escape: when cancer cells hijack the genes for chemotaxis and motility. Annu Rev Cell Dev Biol 21: 695-718, 2005.

2. Wittekind $\mathrm{C}$ and Neid M: Cancer invasion and metastasis. Oncology 69 (Suppl 1): 14-16, 2005.

3. Ludwig T: Local proteolytic activity in tumor cell invasion and metastasis. Bioessays 27: 1181-1191, 2005.

4. Minn AJ, Kang Y, Serganova I, et al: Distinct organ-specific metastatic potential of individual breast cancer cells and primary tumors. J Clin Invest 115: 44-55, 2005.

5. Puricelli L, Gomez DE, Vidal MC, et al: Effect of hostorgan environment on the in vivo and in vitro behavior of a murine mammary adenocarcinoma. Tumour Biol 15: 284-293, 1994.

6. Ladeda V, Adam AP, Puricelli L and Bal de Kier JE: Apoptotic cell death in mammary adenocarcinoma cells is prevented by soluble factors present in the target organ of metastasis. Breast Cancer Res Treat 69: 39-51, 2001.

7. Henrique R, Jeronimo C, Teixeira MR, et al: Epigenetic heterogeneity of high-grade prostatic intraepithelial neoplasia: clues for clonal progression in prostate carcinogenesis. Mol Cancer Res 4: $1-8,2006$.

8. Fidler IJ: Tumor heterogeneity and the biology of cancer invasion and metastasis. Cancer Res 38: 2651-2660, 1978.

9. Bal de Kier Joffe E, Puricelli L, Vidal MC and De Lustig ES: Characterization of two murine mammary tumors with different metastatic ability. J Exp Clin Cancer Res 2: 151-160, 1983.

10. Urtreger AJ, Ladeda VE, Puricelli LI, et al: Modulation of fibronectin expression and proteolytic activity associated to the invasive and metastatic phenotype in two new murine mammary tumor cell lines. Int J Oncol 11: 489-496, 1997.

11. Werbajh SE, Urtreger AJ, Puricelli LI, De Lustig ES, Bal de Kier Joffe E and Kornblihtt AR: Downregulation of fibronectin transcription in highly metastatic adenocarcinoma cells. FEBS Lett 440: 277-281, 1998.

12. Muro A, Puricelli L, Kornblihtt AR and Bal de Kier Joffe E: Inverse correlation between fibronectin mRNA levels and the metastatic potential of two murine mammary adenocarcinomas. Invasion Metastasis 11: 281-287, 1991.
13. Bal de Kier Joffe E, Puricelli L and De Lustig ES: Modified adhesion behavior after in vitro passage of two related murine mammary adenocarcinomas with different metastasizing ability. Invasion Metastasis 6: 302-312, 1986.

14. Pereyra-Alfonso S, Haedo A and Bal de Kier JE: Correlation between urokinase-type plasminogen activator production and the metastasizing ability of two murine mammary adenocarcinomas. Int J Cancer 42: 59-63, 1988.

15. Daroqui MC, Puricelli LI, Urtreger AJ, Elizalde PV, Lanuza GM and Bal de Kier Joffe E: Involvement of TGF-beta(s)/ $\mathrm{T}$ (beta)Rs system in tumor progression of murine mammary adenocarcinomas. Breast Cancer Res Treat 80: 287-301, 2003.

16. Kaspar M, Zardi L and Neri D: Fibronectin as target for tumor therapy. Int J Cancer 118: 1331-1339, 2006.

17. Urtreger A, Porro F, Puricelli L, et al: Expression of RGD minus fibronectin that does not form extracellular matrix fibrils is sufficient to decrease tumor metastasis. Int J Cancer 78: 233-241, 1998.

18. Uehara H, Kim SJ, Karashima T, et al: Effects of blocking platelet-derived growth factor-receptor signaling in a mouse model of experimental prostate cancer bone metastases. J Natl Cancer Inst 95: 458-470, 2003.

19. Yu J, Moon A and Kim HR: Both platelet-derived growth factor receptor (PDGFR)-alpha and PDGFR-beta promote murine fibroblast cell migration. Biochem Biophys Res Commun 282: 697-700, 2001

20. Stark GR, Kerr IM, Williams BR, Silverman RH and Schreiber RD: How cells respond to interferons. Annu Rev Biochem 67: 227-264, 1998.

21. Huang S, Bucana CD, van Arsdall M and Fidler IJ: Stat 1 negatively regulates angiogenesis, tumorigenicity and metastasis of tumor cells. Oncogene 21: 2504-2512, 2002.

22. Pansky A, Hildebrand P, Fasler-Kan E, et al: Defective JakSTAT signal transduction pathway in melanoma cells resistant to growth inhibition by interferon-alpha. Int J Cancer 85: 720-725, 2000

23. Wu F, Li JQ, Miki H, et al: p107 expression in colorectal tumours rises during carcinogenesis and falls during invasion. Eur $\mathbf{J}$ Cancer 38: 1838-1848, 2002.

24. Botos J, Barhoumi R, Burghardt R and Kochevar DT: Rb localization and phosphorylation kinetics correlate with the cellular phenotype of cultured breast adenocarcinoma cells. In Vitro Cell Dev Biol Anim 38: 235-241, 2002.

25. Berx G and van Roy F: The E-cadherin/catenin complex: an important gatekeeper in breast cancer tumorigenesis and malignant progression. Breast Cancer Res 3: 289-293, 2001

26. Lim SC and Lee MS: Significance of E-cadherin/beta-catenin complex and cyclin D1 in breast cancer. Oncol Rep 9: 915-928, 2002.

27. Cavallaro $\mathrm{U}$ and Christofori G: Cell adhesion in tumor invasion and metastasis: loss of the glue is not enough. Biochim Biophys Acta 1552: 39-45, 2001

28. Indinnimeo M, Cicchini C, Stazi A, et al: Prognostic impact of CD31 antigen expression in anal canal carcinoma. Hepatogastroenterology 48: 1355-1358, 2001.

29. Tang DG, Chen YQ, Newman PJ, et al: Identification of PECAM-1 in solid tumor cells and its potential involvement in tumor cell adhesion to endothelium. J Biol Chem 268: 22883-22894, 1993.

30. Righi L, Deaglio S, Pecchioni C, et al: Role of CD31/platelet endothelial cell adhesion molecule-1 expression in in vitro and in vivo growth and differentiation of human breast cancer cells. Am J Pathol 162: 1163-1174, 2003.

31. Alonso DF, Farias EF, Ladeda V, Davel L, Puricelli L and Bal de Kier JE: Effects of synthetic urokinase inhibitors on local invasion and metastasis in a murine mammary tumor model. Breast Cancer Res Treat 40: 209-223, 1996.

32. Monitto CL, Berkowitz D, Lee KM, et al: Differential gene expression in a murine model of cancer cachexia. Am J Physiol Endocrinol Metab 281: E289-E297, 2001.

33. Akiyama SK, Olden K and Yamada KM: Fibronectin and integrins in invasion and metastasis. Cancer Metastasis Rev 14: 173-189, 1995.

34. Christensen L: The distribution of fibronectin, laminin and tetranectin in human breast cancer with special attention to the extracellular matrix. APMIS 26 (Suppl): 1-39, 1992.

35. Wierzbicka-Patynowski I and Schwarzbauer JE: The ins and outs of fibronectin matrix assembly. J Cell Sci 116: 3269-3276, 2003 
36. Akamatsu H, Ichihara-Tanaka K, Ozono K, Kamiike W, Matsuda H and Sekiguchi K: Suppression of transformed phenotypes of human fibrosarcoma cells by overexpression of recombinant fibronectin. Cancer Res 56: 4541-4546, 1996.

37. Zhao H, Jhanwar-Uniyal M, Datta PK, et al: Expression profile of genes associated with antimetastatic gene: nm23-mediated metastasis inhibition in breast carcinoma cells. Int J Cancer 109: 65-70, 2004.

38. Schalken JA, Ebeling SB, Isaacs JT, et al: Down modulation of fibronectin messenger RNA in metastasizing rat prostatic cancer cells revealed by differential hybridization analysis. Cancer Res 48: 2042-2046, 1988.

39. Urtreger AJ, Aguirre Ghiso JA, Werbajh SE, Puricelli LI, Muro AF and Bal de Kier Joffe E: Involvement of fibronectin in the regulation of urokinase production and binding in murine mammary tumor cells. Int J Cancer 82: 748-753, 1999.

40. Muro AF, Bernath VA and Kornblihtt AR: Interaction of the -170 cyclic AMP response element with the adjacent CCAAT box in the human fibronectin gene promoter. J Biol Chem 267: 12767-12774, 1992.
41. Wasenius VM, Hemmer S, Kettunen E, Knuutila S, Franssila K and Joensuu H: Hepatocyte growth factor receptor, matrix metalloproteinase-11, tissue inhibitor of metalloproteinase-1, and fibronectin are up-regulated in papillary thyroid carcinoma: a cDNA and tissue microarray study. Clin Cancer Res 9: 68-75, 2003.

42. Mackay A, Jones C, Dexter T, et al: cDNA microarray analysis of genes associated with ERBB2 (HER2/neu) overexpression in human mammary luminal epithelial cells. Oncogene 22: 2680-2688, 2003.

43. Hao X, Sun B, Hu L, et al: Differential gene and protein expression in primary breast malignancies and their lymph node metastases as revealed by combined cDNA microarray and tissue microarray analysis. Cancer 100: 1110-1122, 2004. 